\title{
Anthocyanin-rich Phytochemicals from Aronia Fruits Inhibit Visceral Fat Accumulation and Hyperglycemia in High-fat Diet-induced Dietary Obese Rats
}

\author{
Azusa Takahashi ${ }^{1}$, Hisae Shimizu ${ }^{2}$, Yukako Okazaki ${ }^{3}$, Hirohide Sakaguchi ${ }^{4}$, \\ Toshio Taira $^{5}$, Takashi Suzuki ${ }^{1}$ and Hideyuki Chiji ${ }^{2, *}$ \\ ${ }^{1}$ Division of Agrobiology, Graduate School of Agriculture, Hokkaido University, Kita9 Nishi-9, Kita-ku, Sapporo, Hokkaido 060-8589, JAPAN \\ ${ }^{2}$ Department of Food Science and Human Nutrition Faculty of Human Life Science, Fuji Women's University, 4-5-7 Hanakawa-minami, Ishikari, \\ Hokkaido 061-3204, JAPAN \\ ${ }^{3}$ Deprtment of Human Life Science Faculty of Human Life Science, Fuji Women's University, 4-5-7 Hanakawa-minami, Ishikari, Hokkaido \\ 061-3204, JAPAN \\ ${ }^{4}$ Nihonshinyaku Co., Ltd., 14 Nishinosho-monguchi-cho, kisshoin, Minami-ku, Kyoto, Kyoto 601-8550, JAPAN \\ ${ }^{5}$ COSMO BIO Co., Ltd., YS BIdg, 1-12 Kita12, Nishimachi, Nishi-ku, Sapporo, Hokkaido 063-0061, JAPAN
}

\begin{abstract}
Aronia fruits (chokeberry: Aronia melanocarpa E.) containing phenolic phytochemicals, such as cyanidin 3-glycosides and chlorogenic acid, have attracted considerable attention because of their potential human health benefits in humans including antioxidant activities and ability to improved vision. In the present study, the effects of anthocyanin-rich phytochemicals from aronia fruits (aronia phytochemicals) on visceral fat accumulation and fasting hyperglycemia were examined in rats fed a high-fat diet (Experiment 1). Total visceral fat mass was significantly lower in rats fed aronia phytochemicals than that in both the control group and bilberry phytochemicals-supplemented rats $(p<0.05)$. Moreover, perirenal and epididymal adipose tissue mass in rats fed aronia phytochemicals was significantly lower than that in both the control and bilberry phytochemicals group. Additionally, the mesenteric adipose tissue mass in aronia phytochemicals-fed rats was significantly low $(p<0.05)$. Furthermore, the fasting blood glucose levels significantly decreased in rats fed aronia phytochemicals for 4 weeks compared to that in the control rats $(p$ $<0.05$ ). Therefore, we investigated the effects of phytochemicals on postprandial hyperlipidemia after corn oil loading in rats, pancreatic lipase activity in vitro, and the plasma glycemic response after sucrose loading in order to elucidate the preventive factor of aronia phytochemical on visceral fat accumulation. In the oral corn oil tolerance tests (Experiment 2), aronia phytochemicals significantly inhibited the increases in plasma triglyceride levels, with a half-maximal inhibitory concentration $\left(\mathrm{IC}_{50}\right)$ of $1.50 \mathrm{mg} / \mathrm{mL}$. However, the inhibitory activity was similar to that of bilberry and tea catechins. In the sucrose tolerance tests (Experiment 3), aronia phytochemicals also significantly inhibited the increases in blood glucose levels that were observed in the control animals $(p<0.05)$. These results suggest that anthocyanin-rich phytochemicals in aronia fruits suppress visceral fat accumulation and hyperglycemia by inhibiting pancreatic lipase activity and/or intestinal lipid absorption.
\end{abstract}

Key words: Aronia, phytochemicals, anthocyanin, visceral fat accumulation, postprandial hyperlipidemia

1 INTRODUCTION

Aronia (chokeberry: Aronia melanocarpa E.) is a deciduous shrub native to North America. In Hokkaido, North Japan, the red-purple fruits are widely consumed as juice, wines and jams. The red-purple color of aronia fruits is attributed to the presence of cyanidin 3-glycosides, which show potent antioxidant activity. Recent studies of antho- cyanin have elucidated its biological activities and possible health benefits. These include protection against chronic diseases such as cancer $^{1)}$, cardio vascular disease ${ }^{2)}$, atherosclerosis $^{3)}$ and diabetes ${ }^{4)}$.

We previously reported the protective effects of aronia pigments following ethanol-induced gastric injury ${ }^{5)}$ and the cholesterol lowering effects of the anthocyanin metabolite

\footnotetext{
* Correspondence to: Hideyuki Chiji, Department of Food Science and Human Nutrition Faculty of Human Life Science, Fuji Women's University, 4-5-7 Hanakawa-minami, Ishikari, Hokkaido 061-3204, JAPAN

E-mail: hchiji@fujijoshi.ac.jp

Accepted September 16, 2015 (received for review July 25, 2015)

Journal of Oleo Science ISSN 1345-8957 print / ISSN 1347-3352 online

http://www.jstage.jst.go.jp/browse/jos/ http://mc.manusriptcentral.com/jjocs
} 


\section{A. Takahashi, H. Shimizu and Y. Okazaki et al.}

protocatechuic acid in animals and humans ${ }^{6)}$. Moreover, we observed the protective properties of anthocyanin-rich phytochemicals from haskap fruits in rats with metabolic syndrome $^{7)}$ and the protective effects of aronia and haskap phytochemicals in rats with potassium bromate $\left(\mathrm{KBrO}_{3}\right)$ -induced renal damage ${ }^{8)}$.

The antioxidant effects of aronia fruits have been investigated in component analyses ${ }^{9,10)}$. However, the effects of aronia on visceral fat accumulation, postprandial hyperlipidemia and hyperglycemia in rats with high-fat diet-induced obesity have not been demonstrated.

In the present study, we induced obesity in rats via a high-fat diet and determined whether aronia phytochemicals ameliorate the resulting obesity (Experiment 1). In addition, we identified anti-obesity effectors among the aronia phytochemicals using oral corn oil tolerance tests in rats, and in vivo pancreatic lipase inhibition assays (Experiment 2). Finally, we investigated the effects of the aronia phytochemicals on the postprandial hyperglycemia after sucrose loading in rats (Experiment 3).

\section{MATERIALS AND METHODS}

\subsection{Materials}

Aronia phytochemicals were extracted and analyzed using high performance lipid chromatography (HPLC) and liquid chromatography-mass spectroscopy (LC-MS) as described previously $^{8,11}$. Identified anthocyanins in aronia phytochemicals included cyanidin 3-galactoside, cyanidin 3-arabinoside, and cyanidin 3-glucoside, which were present in anthocyanin preparations at $579.1 \mathrm{mmol} / \mathrm{g}$ as cyanidin 3-glucoside. Other polyphenols included chlorogenic $\operatorname{acid}(32.7 \mathrm{mmol} / \mathrm{g}),(+)$ catechin $(10.7 \mathrm{mmol} / \mathrm{g})$, and caffeic acid $(13.9 \mathrm{mmol} / \mathrm{g})$. Anthocyanins in bilberry phytochemicals were used as a positive control and included cy- anidin 3-glucoside, cyanidin 3-galactoside, pelargonidin 3-glucoside, peonidin 3-galactoside, delphinidin 3-galactoside, petunidin 3-glucoside and malvidin 3-galactoside. The total anthocyanin content was $824.2 \mathrm{mmol} / \mathrm{g}$ as cyanidin 3-glucoside.

\section{EXPERIMENTAL DESIGN}

3.1 Suppressive effects of aronia phytochemicals on visceral fat accumulation and fasting hyperglycemia in rats (Experiment 1)

Male Sprague-Dawley rats (4 weeks-old) were purchased from Charles River Japan, Inc. (Yokohama, Japan). All animals were housed individually in cages with a 12:12-hr light: dark cycle. Temperature and humidity were controlled at $23 \pm 11^{\circ} \mathrm{C}$ and $55 \% \pm 10 \%$, respectively. The rats were randomly divided into three groups of six animals. There were no significant differences in body weights, serum triglyceride concentrations, cholesterol concentrations and blood glucose levels between groups at the start of the experimental period. The composition of the experimental diet was as follows (grams per $100 \mathrm{~g}$ ): casein, 25; corn oil, 5; lard, 20; fiber, 5; mineral mixture, 3.5 (AIN-93) ${ }^{12)}$; vitamin mixture, 1 (AIN-93 $)^{12)}$; choline chloride, 0.25 ; and sucrose to 100 . The experimental groups were fed for 4 weeks on one of the following diets that contained $0.4 \%$ anthocyanins of aronia or bilberry phytochemicals. The compositions of aronia and bilberry phytochemicals (grams per $100 \mathrm{~g}$ ) are shown in Table 1. The rats were provided free access to experimental diets and water for 4 weeks. Body weight and food consumption were recorded daily. This experimental design was approved by the Animal Experiment Committee, Fuji Women's University and the rats were maintained in accordance with the guidelines.

At the end of the 4-week experiment, blood samples

Table 1 Composition of experimental high-fat diets.

\begin{tabular}{lccc}
\hline & Control & $\begin{array}{c}\text { Aronia } \\
\text { phytochemicals }\end{array}$ & $\begin{array}{c}\text { Bilberry } \\
\text { phytochemicals }\end{array}$ \\
\hline Casein & 250.0 & 250.0 & 250.0 \\
Mineral mix* & 35.0 & 35.0 & 35.0 \\
Vitamin mix* & 10.0 & 10.0 & 10.0 \\
Choline chloride & 2.5 & 2.5 & 2.5 \\
Corn oil & 50.0 & 50.0 & 50.0 \\
Lard & 200.0 & 200.0 & 200.0 \\
Cellulose & 50.0 & 50.0 & 50.0 \\
Aronia phytochemicals & - & 17.4 & - \\
Bilberry phytochemicals & - & - & 10.6 \\
Sucrose & to 1000 & to 1000 & to 1000 \\
\hline
\end{tabular}

*Mineral mixture and vitamin mixture prepared according to AIN 93-G ${ }^{12)}$. 
were collected from the abdominal aorta. The serum was prepared by centrifugation at $2000 \times \mathrm{g}$ for $20 \mathrm{~min}$. Serum triglycerides, total cholesterol concentrations, low-density lipoprotein (LDL) and high-density lipoprotein (HDL) cholesterol concentrations, and blood glucose levels were analyzed by SRL, Inc., Sapporo, Japan.

\subsection{Antihyperlipidemic effects of aronia phytochemicals in oral fat tolerance tests and in vitro pancreatic lipase activity assays (Experiment 2)}

Eighteen 7-weeks-old male Sprague-Dawley rats with an average body weight of $200 \mathrm{~g}$ were provided to a standard laboratory diet and water ad libitum for 1 week. The rats were divided into a control group, aronia or bilberry phytochemical-administered (containing anthocyanin $300 \mathrm{mg} / \mathrm{kg}$ body weight) groups (six rats in each group). They were fasted for $24 \mathrm{~h}$ prior to the corn oil emulsion load experiments, which were performed according to Han's method $^{13)}$. Corn oil emulsions ( $3 \mathrm{~mL}$ corn oil, $50 \mathrm{mg}$ sodium cholate, and $3 \mathrm{~mL}$ water) were orally administered (12.5 $\mathrm{mL} / \mathrm{kg}$ of body weight) and blood samples were collected from the tail veins without an anesthetic at 0, 30, 60, 120, 180, and 240 min after the administration. Serum triglyceride concentrations were measured using a Fuji Dri-Chem 3500V (Fujifilm Corp. Tokyo, Japan) and lipase activity was measured using a porcine pancreatic lipase (Sigma-Aldrich, St Louis, MO, USA) according to the method described by Kawasaki et $a l .{ }^{14)}$.

\subsection{Antihyperglycemic effects of aronia phytochemicals in oral sucrose tolerance tests (experiment 3)}

The oral sucrose tolerance tests were performed to determine the short-term effect of aronia phytochemicals on normal rats. Seven-week-old male Sprague-Dawley rats were fed a standard laboratory diet with water ad libitum and were fasted for $24 \mathrm{~h}$ before the experiments. Rats were randomly divided into three groups (six rats in each group). The first group served as a control and rats were administered normal saline (10 mL/kg oral administration) while the other two groups were treated with aronia phytochemicals and bilberry phytochemicals (containing anthocyanin $300 \mathrm{mg} / \mathrm{kg}$ body weight) respectively. Normal saline, aronia phytochemicals and bilberry phytochemicals were administered $30 \mathrm{~min}$ prior to the oral sucrose load ( $2 \mathrm{~g} / \mathrm{kg}$ body weight at $10 \mathrm{~mL} / \mathrm{kg}$ ). At each sampling point up to $120 \mathrm{~min}, 5 \mu \mathrm{L}$ of blood samples was obtained from tail veins and blood glucose levels were immediately measured using a disposable glucose sensor (Glutest Pro, Sanwa Chemical, Co., Tokyo, Japan).

\section{STATISTICAL ANALYSIS}

All results are expressed as mean \pm standard error of the mean (SE). Differences between groups were identified using one-way analysis of variance (ANOVA) followed by Tukey-Kramer post-hoc tests. Differences were considered significant when P-values of $<0.05$ were obtained. All statistical analyses were performed using Stat View 5.0 software (SAS Institute, Cary, NC).

\section{RESULTS AND DISCUSSION}

5.1 Suppressive effect of aronia phytochemicals on visceral fat accumulation and hyperglycemia in rats (Experiment 1)

As shown in Table 2, no differences in final body weights, or feed efficiency were observed between the treatments groups. However, food intake tended to be lower in rats fed berry phytochemicals than in those fed a high-fat diet control. Total visceral fat accumulations and organ mass are shown for each treatment group in Table 3. No significant differences in the liver and the kidney mass were observed between the treatments groups. Perirenal adipose tissue mass was significantly lower in rats fed aronia phytochemicals than that in those fed a high-fat diet with or without bilberry. In addition, wet epididymal

Table 2 Effects of consuming aronia phytochenmicals on body weight and food intake in rats for 4 weeks.

\begin{tabular}{lccc}
\hline & Control & $\begin{array}{c}\text { Aronia } \\
\text { phytochemicals }\end{array}$ & $\begin{array}{c}\text { Bilberry } \\
\text { phytochemicals }\end{array}$ \\
\hline $\begin{array}{l}\text { Final body weight (g) } \\
\begin{array}{l}\text { Body weight gain } \\
\text { (g/ 4 weeks) }\end{array}\end{array}$ & $374.86 \pm 11.26$ & $342.62 \pm 4.53$ & $350.92 \pm 12.71$ \\
$\begin{array}{l}\text { Food intake } \\
\text { (g/ 4 weeks) }\end{array}$ & $522.54 \pm 17.45$ & $483.18 \pm 9.74$ & $505.89 \pm 15.24$ \\
$\begin{array}{l}\text { Feed efficiency } \\
\text { (body weight gain g/g diet) }\end{array}$ & $0.46 \pm 0.01$ & $0.49 \pm 0.01$ & $0.47 \pm 0.01$ \\
\hline
\end{tabular}

Each value is the mean $\pm \mathrm{SE}, n=6$. Data were analyzed with ANOVA $(p<0.05)$. 


\section{A. Takahashi, H. Shimizu and Y. Okazaki et al.}

Table 3 Effects of aronia phytochenmicals treatment on visceral fat accumulation and organ mass in rats fed a high-fat diet for 4 weeks.

\begin{tabular}{lccc}
\hline & Control & $\begin{array}{c}\text { Aronia } \\
\text { phytochemicals }\end{array}$ & $\begin{array}{c}\text { Bilberry } \\
\text { phytochemicals }\end{array}$ \\
\hline Liver (g) & $12.73 \pm 0.53$ & $12.01 \pm 0.31$ & $11.65 \pm 0.52$ \\
Liver (g/ 100 g B.W.) & $3.51 \pm 0.07$ & $3.51 \pm 0.07$ & $3.32 \pm 0.07$ \\
Kidney (g) & $2.38 \pm 0.11$ & $2.20 \pm 0.04$ & $2.29 \pm 0.10$ \\
Kidney (g/ 100 g B.W.) & $0.66 \pm 0.01$ & $0.64 \pm 0.01$ & $0.65 \pm 0.01$ \\
$\begin{array}{l}\text { Perirenal adipose tissue } \\
\text { (g/ 100 g B.W.) }\end{array}$ & $2.78 \pm 0.07^{\mathrm{a}}$ & $2.05 \pm 0.13^{\mathrm{b}}$ & $2.44 \pm 0.07^{\mathrm{a}}$ \\
$\begin{array}{l}\text { Epididymal adipose tissue } \\
\text { (g/ 100 g B.W.) }\end{array}$ & $2.36 \pm 0.15^{\mathrm{a}}$ & $1.73 \pm 0.10^{\mathrm{b}}$ & $2.36 \pm 0.14^{\mathrm{a}}$ \\
$\begin{array}{l}\text { Mesenteric adipose tissue } \\
\text { (g/ } 100 \text { g B.W.) }\end{array}$ & $1.60 \pm 0.09^{\mathrm{a}}$ & $1.30 \pm 0.06^{\mathrm{b}}$ & $1.59 \pm 0.06^{\mathrm{a}}$ \\
$\begin{array}{l}\text { Total visceral fat } \\
\text { (g/ } 100 \text { g B.W.) }\end{array}$ & $6.74 \pm 0.16^{\mathrm{a}}$ & $5.08 \pm 0.28 \mathrm{~b}$ & $6.39 \pm 0.25^{\mathrm{a}}$ \\
\hline
\end{tabular}

Each value is the mean $\pm \mathrm{SE}, n=6$. Data were analyzed with ANOVA $(p<0.05)$.

Table 4 Effects of aronia phytochemicals treatment on serum biomarkers in rats fed a high-fat diet for 4 weeks.

\begin{tabular}{lccc}
\hline & Control & $\begin{array}{c}\text { Aronia } \\
\text { phytochemicals }\end{array}$ & $\begin{array}{c}\text { Bilberry } \\
\text { phytochemicals }\end{array}$ \\
\hline Serum total cholesterol (mM/dL) & $1.73 \pm 0.12$ & $1.68 \pm 0.08$ & $1.73 \pm 0.20$ \\
Serum HDL cholesterol (mM/dL) & $0.51 \pm 0.02$ & $0.51 \pm 0.01$ & $0.53 \pm 0.06$ \\
Serum LDL cholesterol (mM/dL) & $1.22 \pm 0.10^{\mathrm{a}}$ & $1.17 \pm 0.07$ & $1.20 \pm 0.14^{\mathrm{a}}$ \\
Serum triglyceride (mM/dL) & $0.83 \pm 0.14$ & $0.81 \pm 0.06$ & $0.80 \pm 0.08$ \\
Serum glucose (mM/dL) & $9.17 \pm 0.38^{\mathrm{a}}$ & $8.20 \pm 0.31^{\mathrm{b}}$ & $8.47 \pm 0.42^{\mathrm{ab}}$ \\
\hline
\end{tabular}

Each value is the mean $\pm \mathrm{SE}, n=6$. Data were analyzed with ANOVA $(p<0.05)$.

adipose tissue mass was lower in rats fed aronia phytochemicals than that in control and bilberry groups. Moreover, mesenteric adipose tissue mass was significantly lower in rats fed aronia phytochemicals than that in control rats, and total visceral fats mass was lower in rats fed aronia phytochemicals than that in the control and bilberry groups. These data suggest that long-term administration of aronia phytochemicals prevent visceral fat accumulation. In a previous study of anthocyanin and obesity, Tsuda et al. showed that the pigment of purple corn, containing high levels of cyanidin 3-glucoside, ameliorated obesity by suppressing mRNA expression of enzymes involved in fatty acid and triacylglycerol synthesis ${ }^{15}$. Moreover, Wang et al. showed that cyanidin 3-glucoside reduced hyperlipidemia in rats ${ }^{16)}$ and Quin et al. reported that chokeberry extracts attenuated epididymal adipose tissue accumulation in rats fed a fructose-rich diet ${ }^{17)}$. Antiobesity properties of chloro- genic acid and proanthocyanidin, constituents of aronia phytochemicals, have also been reported ${ }^{18-21)}$. Hence, aronia phytochemicals, which include various polyphenols such as anthocyanin, are expected to have similar properties. These reports and the present study suggest that the anti-visceral fat accumulation effects of aronia phytochemicals are synergistic because anthocyanin and other polyphenols of aronia cumulatively inhibit the absorption of lipids in the intestine.

Also, Islam et al. showed that metabolic disease reflects the composition of the gastrointestinal microbiota in rats with high-fat diets-induced obesity ${ }^{22}$.

Treatment of rats with high-fat diet-induced obesity with aronia phytochemicals resulted in a significant decrease in blood glucose levels (Table 4). No differences in serum triglyceride, total and HDL cholesterol concentration, and liver lipids (Table 5) were observed between the treatment 
Table 5 Effects of consuming aronia phytochemicals on liver lipid in rats fed a highfat diet for 4 weeks.

\begin{tabular}{lccc}
\hline & Control & $\begin{array}{c}\text { Aronia } \\
\text { phytochemicals }\end{array}$ & $\begin{array}{c}\text { Bilberry } \\
\text { phytochemicals }\end{array}$ \\
\hline Total cholesterol $(\mu \mathrm{mol} / \mathrm{g}$ liver $)$ & $7.08 \pm 0.68$ & $7.16 \pm 0.61$ & $7.29 \pm 0.67$ \\
Triglyceride $(\mu \mathrm{mol} / \mathrm{g}$ liver $)$ & $38.38 \pm 7.25$ & $38.08 \pm 3.68$ & $38.71 \pm 2.49$ \\
\hline
\end{tabular}

Each value is the mean $\pm \mathrm{SE}, n=6$. Data were analyzed with ANOVA $(p<0.05)$.

groups. However, rats fed aronia phytochemicals had significantly lower serum LDL cholesterol concentrations than those fed a high-fat control diet with or without bilberry phytochemicals. Previously, we showed that dietary haskap phytochemicals suppress postprandial hyperlipidemia and hyperglycemia in rats fed a high-fat and high-sucrose diet ${ }^{7)}$. Similarly, Quin et al. have reported that anthocyanin supplementation improves LDL and HDL cholesterol concentrations and enhances cellular cholesterol efflux to serum in humans ${ }^{23)}$. Ohta et al. also showed that the total serum cholesterol concentrations in rats fed a high-cholesterol diet were lowered by supplementation with apple polyphenol indicating the mechanisms underlying control of cholesterol absorption by polyphenols ${ }^{24)}$. The present data suggests that anthocyanin and other polyphenols in the aronia phytochemicals have similar LDL cholesterol-lowering effects as those documented for tea catechin and apple polyphenol.

\subsection{Antihyperlipidemic effects of aronia phytochemicals in} oral fat tolerance tests, in vitro pancreatic lipase assays and oral sucrose tolerance tests (Experiment 2)

In the Experiment 1, we demonstrated that 4-week administration of aronia phytochemicals suppressed visceral fat accumulation and increases in blood glucose. To elucidate the antiobesity mechanism of aronia phytochemicals, we performed oral fat tolerance tests and evaluated the inhibitory effect of aronia phytochemicals on activity of pancreatic lipase, a key enzyme in lipid metabolism. As shown in Fig. 1, serum triglyceride concentrations were significantly lowered after treatment with aronia phytochemicals 30-240 min after lipid loading compared to that in the control group $(0.9 \% \mathrm{NaCl})$. The area under the curve (AUC) was calculated after individual oral fat tolerance test and blood triglyceride concentrations were determined incrementally between 0 to 240 min. Supplementation with aronia phytochemicals significantly reduced AUC compared to the control rats $(11,805 \pm 1,313 \mathrm{mg} / \mathrm{dL} \cdot \mathrm{min}$ and $19,937 \pm 2,470 \mathrm{mg} / \mathrm{dL} \cdot \mathrm{min}$, respectively). However, no significant differences in AUC were observed between animals supplemented with aronia phytochemicals and bilberry phytochemicals $(11,892 \pm 1,489 \mathrm{mg} / \mathrm{dL} \cdot \min )$. In accord with these results, Tosca et al. showed improved serum tri-

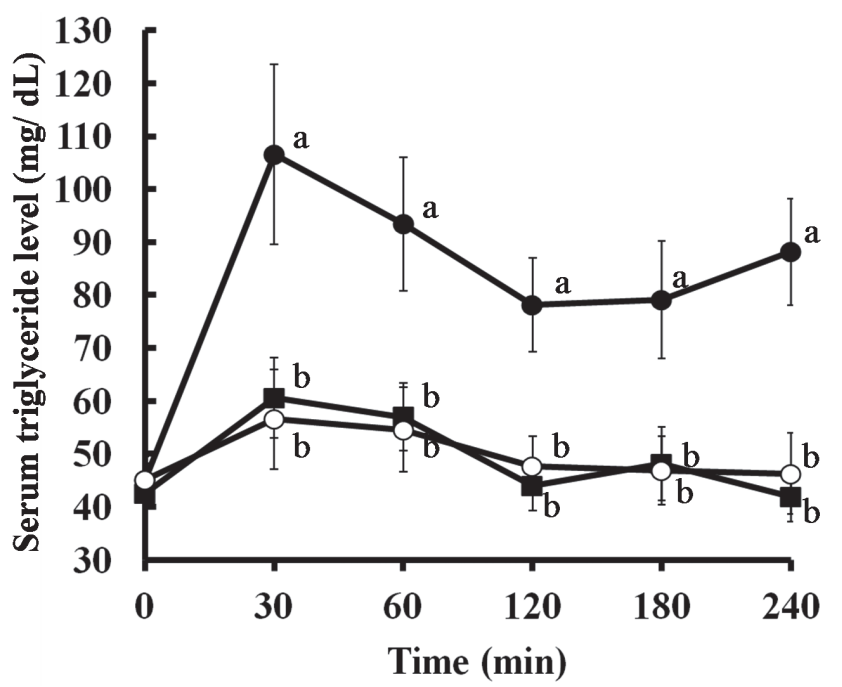

Fig. 1 Effects of aronia phytochemicals on rat serum triglyceride levels after oral administration of lipid emulsion. $\square$, Five milliliter of a aronia phytochemicals (300 mg/kg B.W. anthocyanin) was dosed in male 7 week-old SD rats. After 30 minutes, corn oil emulsion ( $2 \mathrm{~mL} / 160 \mathrm{~g} \mathrm{~B}$. W.) was administered to each rat. $\bigcirc$, Bilberry phytochemicals (300 mg/kg B. W. anthocyanin). - Control was administered with the same volume of $0.9 \% \mathrm{NaCl}$ solution. Each value is the mean $\pm \mathrm{SE}, n=6$. Those not sharing a letter differ, $p<0.05$.

glyceride levels in guinea pigs administered grape polyphenol $^{19)}$. Similarly, Noguchi et al. showed decreased serum triglyceride concentrations in rats fed boysenberries reflecting inhibition of intestinal fat absorption by boysenberry components ${ }^{25)}$. Hence, to assess whether aronia polyphenol phytochemicals such as anthocyanin exert similar effects, we investigated the effect of aronia phytochemicals on pancreatic lipase activity (Table 6). In these experiments, $\mathrm{IC}_{50}$ value of the aronia phytochemicals preparation was $1.50 \pm 0.01 \mathrm{mg} / \mathrm{mL}$, which is similar to that of the tea catechin $(1.86 \pm 0.02 \mathrm{mg} / \mathrm{mL})$ and is higher than that of protocatechuic acid $(2.89 \pm 0.08 \mathrm{mg} / \mathrm{mL})$ and gallic acid $(2.64 \pm 0.02 \mathrm{mg} / \mathrm{mL})$. After consumption, triglycerides are 
Table 6 Effects of aronia phytochemicals and phenolic components on pancreatic lipase activity.

\begin{tabular}{lc}
\hline & $\begin{array}{c}\text { Pancreatic lipase activity IC50 value } \\
(\mathrm{mg} / \mathrm{mL})\end{array}$ \\
\hline Aronia phytochemicals & $1.50 \pm 0.01$ \\
Bilberry phytochemicals & $1.67 \pm 0.04$ \\
Gallic acid & $2.64 \pm 0.04$ \\
Protocatechuic acid & $2.89 \pm 0.08$ \\
Tea catechin & $1.86 \pm 0.02$ \\
\hline
\end{tabular}

Each value is the mean $\pm \mathrm{SD}, n=3$.

degraded into fatty acids and monoglycerides by pancreatic lipase and form bile acid micelles that are absorbed by small intestinal epithelial cells. Because anthocyanin also inhibits pancreatic lipase activity ${ }^{26,27)}$, these observations suggest that aronia phytochemicals inhibit the increases in postprandial serum triglycerides and that anthocyanin inhibits enzymes such as lipase. However, no differences in pancreatic lipase activity were observed between the aronia and the bilberry phytochemicals-treated groups. Unidentified polyphenolic polymers and other constituents in the aronia phytochemicals may affect the improvement of visceral fat accumulation in rats. On the other hand, Taira et al. showed that the composition of intestinal microbiota in rats fed aronia phytochemicals ameliorated the disturbance caused by a high-fat diet ${ }^{28)}$. These results suggest that some aronia phytochemicals escaped from gastric digestion play a significant role in the prevention of degenerative disease by improving colonic environment.

Accordingly, the present antihyperlipidemic observations of aronia phytochemicals markedly increased in obese animals.

\subsection{Antihyperglycemic effects of aronia phytochemicals in oral sucrose tolerance tests (experiment 3)}

Long-term supplementation with aronia phytochemicals significantly reduced blood glucose levels in rats fed a highfat and high-sucrose diet (experiment 1). Thus, we investigated the antihyperglycemic effects of aronia phytochemicals by evaluating the blood glucose levels of rats after sucrose loading. These experiments showed that the blood glucose levels at $30 \mathrm{~min}$ post sucrose loading were significantly lower in rats receiving the diet supplemented with aronia phytochemicals than that in the control rats (Fig. 2). Subsequently, AUCs were calculated after each oral sucrose tolerance test to determine blood glucose concentrations from 0 to $120 \mathrm{~min}$. Supplementation with aronia phytochemicals significantly reduced AUC compared to the control and bilberry phytochemicals supplemented rats $(10,840 \pm 580 \mathrm{mg} / \mathrm{dL} \cdot \mathrm{min}, 13,596 \pm 645 \mathrm{mg} / \mathrm{dL} \cdot \mathrm{min}$ and $12,565 \pm 475 \mathrm{mg} / \mathrm{dL} \cdot \mathrm{min}$, respectively). These results

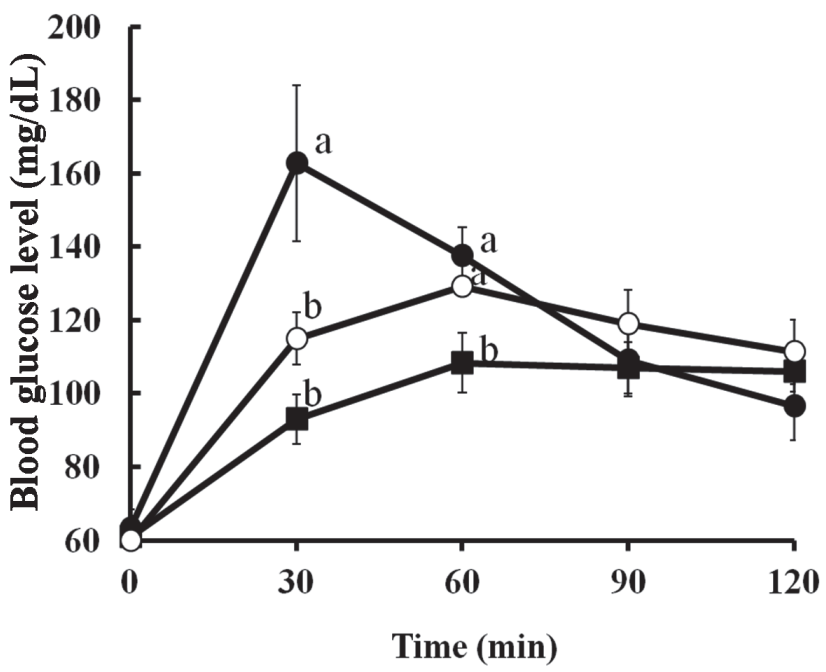

Fig. 2 Effects of aronia phytochemicals on blood glucose level after oral administration of sucrose. $\square$, Five milliliter of a aronia phytochemicals (300 mg/kg B. W. anthocyanin) was dosed in male 7 week-old SD rats. After 30 minutes, $10 \mathrm{~mL}$ of a $2 \mathrm{~g} / \mathrm{kg}$ sucrose solution was administered to each rat. O, Bilberry phytochemicals (300 mg/kg B.W. anthocyanin). , Control was administered with the same volume of $0.9 \% \mathrm{NaCl}$ solution. Each value is the mean $\pm \mathrm{SE}, n=6$. Those not sharing a letter differ, $p<0.05$.

suggest that aronia phytochemicals may have a short-term effect in controlling serum glucose levels. Anthocyanin reportedly inhibits $\alpha$-glucosidase ${ }^{29,30)}$ and the present data and previous studies suggest that aronia phytochemicals inhibit sucrase. Furthermore, Matsui et al. showed that when sweet potato peonidin glucoside was administered following glucose and maltose ingestion, blood glucose levels decreased compared with vehicle, but not sucrose ${ }^{31)}$. However, aronia phytochemicals (mainly cy 3-gal) ameliorated the increase in blood glucose levels in the sucrose 
tolerance test, suggesting that anthocyanins have varied effects on $\alpha$-glucosidase activity. In addition, aronia phytochemicals include chlorogenic acid, which reportedly ameliorates hyperglycemia and type-2 diabetes in animals and human $^{32-34)}$. Taken together, the results suggest that anthocyanin and chlorogenic acid in aronia phytochemicals moderate the increases in blood glucose levels by synergistically inhibiting enzymatic degradation of sucrose in the intestine.

\section{CONCLUSION}

The present experiments demonstrate that aronia phytochemicals suppress visceral fat accumulation and postprandial hyperlipidemia in rats fed a high-fat diet by inhibiting pancreatic lipase activity and/or intestinal lipid absorption. The data suggest that aronia phytochemicals may be an effective crude drug for the treatment of obesity caused by high-fat diets.

Some parts of this study were conducted with the grant of the Grant-in-Aid for Scientific Research B (Grant number 25292017).

\section{REFERENCES}

1) Seeram, N. P.; Adams, L. S.; Zhang, Y.; Lee, R.; Sand, D.; Scheuller, H. S.; Heber, D. Blackberry, black raspberry, blueberry, cranberry, red paspberry, and strawberry extracts inhibit growth and stimulate apoptosis of human cancer cells in vitro. J. Agric. Food Chem. 54, 9329-9339 (2006).

2) Basu, A.; Du, M.; Leyva, M. J.; Sanchez, K.; Betts, N. M.; Wu, M.; Aston, C. E.; Lyons, T. J. Blueberries decrease cardiovascular risk factors in obese men and women with metabolic syndrome. J. Nutr. 140, 1582-1587 (2010).

3) Xia, X.; Ling, W.; Ma, J.; Xia, M.; Hou, M.; Wang, Q.; Zhu, H.; Tang, Z. An anthocyanin-rich extract from black rice enhances antherosclerotic plaque stabilization in apolipoprotein E-deficient mice. J. Nutr. 136, 2220-2225 (2006).

4) Takikawa, M.; Inoue, S.; Horio, F.; Tsuda, T. Dietary anthocyanin-rich bilberry extract ameliorates hyperglycemia and insulin sensitivity via activation of AMPactivated protein kinase in diabetic mice. J. Nutr. 140, 527-533 (2010).

5) Matsumoto, M.; Hara, H.; Chiji, H.; Kasai, T. Gastroprotective effect of red pigments in black chokeberry fruit (Aronia melanocarpa Elliot) on acute gastric hemorrhagic lesions in rats. J. Agric. Food Chem. 52, 22262229 (2004).

6) Tamura, A.; Fukushima, M.; Shimada, K.; Han, K. H.;
Sekikawa, M.; Watanabe, S.; Nakano, M.; Matsumoto, M.; Chiji, H. Cholesterol Metabolism in Rat Is Affected by Protocatechuic Acid. J. Nutr. Sci. Vitaminol. 50, 13-18 (2004).

7) Takahashi, A.; Okazaki, Y.; Nakamoto, A.; Watanabe, S.; Sakaguchi, H.; Tagashira, Y.; Kagii, A.; Nakagawara, S.; Higuchi, O.; Suzuki, T.; Chiji, H. Dietary anthocyaninrich haskap phytochemicals inhibit postprandial hyperlipidemia and hyperglycemia in rats. J. Oleo Sci. 63, 201-209 (2014).

8) Takahashi, A.; Watanabe, J.; Sakaguchi, H.; Okazaki, Y.; Suzuki, T.; Chiji, H. Anthocyanin-enriched extracts from aronia (Aronia melanocarpa E.) and haskap (Lonicera caerulea L.) suppressed KBrO3-induced renal damage in rats. Nippon Shokuhin Kagaku Kogaku Kaishi 62, 235-241 (2015).

9) Krajka-Kuźniak, V.; Szaefer, H.; Ignatowicz, E.; Adamska, T.; Oszmiański, J.; Baer-Dubowska, W. Effect of chokeberry (Aronia melanocarpa) juice on the metabolic activation and detoxication of carcinogenic N-nitrosodiethylamine in rat liver. J. Agric. Food Chem. 57, 5071-5077 (2009).

10) Valcheva-Kuzmanova, S.; Borisova, P.; Galunska, B.; Krasnaliev, I.; Belcheva, A. Hepatoprotective effect of the natural fruit juice from Aronia melanocarpa on carbon tetrachloride-induced acute liver damage in rats. Exp. Toxicol. Pathol. 56, 195-201(2004).

11) Chandra, A.; Rana, J.; Li, Y. Separation, identification, quantification, and method validation of anthocyanins in botanical supplement raw materials by HPLC and HPLC-MS. J. Agric. Food Chem. 49, 3515-3521 (2001).

12) Reeves, P. G.; Nielsen, F. H.; Fahey, G. C. Jr. AIN-93 purified diets for laboratory rodents: final report of the American institute of nutrition ad hoc writing committee on the reformulation of the AIN-76A rodent diet. $J$. Nutr. 123, 1939-1951 (1993).

13) Han, L. K.; Gong, X. J.; Kawano, S.; Saito, M.; Kimura, Y.; Okuda, H. Antiobesity actions of Zingiber officinale Roscoe. YAKUGAKU ZASSHI 125, 213-217 (2005).

14) Kawasaki, K.; Shiromizu, T.; Katsui, M. Suppressive effect of polyphenols extracted from chestnut skins on lipid absorption in rats. Nippon Shokuhin Kagaku Kougaku Kaishi 56, 545-548(2009).

15) Tsuda, T.; Horio, F.; Uchida, K.; Aoki, H.; Osawa, T. Dietary cyanidin $3-O-\beta$-D-glucoside-rich purple corn color prevents obesity and ameliorates hyperglycemia in mice. J. Nutr. 133, 2125-2130 (2003).

16) Wang, Y.; Zhang, Y.; Wang, X.; Liu, Y.; Xia, M. Supplementation with cyanidin-3-O- $\beta$-glucoside protects against hypercholesterolemia-mediated endothelial dysfunction and attenuates atherosclerosis in apolipoprotein E-deficient mice. J. Nutr. 142, 1033-1037 (2012). 


\section{A. Takahashi, H. Shimizu and Y. Okazaki et al.}

17) Qin, B.; Anderson, R. A. An extract of chokeberry attenuates weight gain and modulates insulin, adipogenic and inflammatory signaling pathways in epididymal adipose tissue of rats fed a fructose-rich diet. $\mathrm{Br}$. J. Nutr. 108, 581-587 (2012).

18) Cho, A. S.; Jeon, S. M.; Kim, M. J.; Yeo, J.; Seo, K. I.; Choi, M. S.; Lee, M. K. Chlorogenic acid exhibits antiobesity property and improves lipid metabolism in high-fat diet-induced-obese mice. Food Chem. Toxicol. 48, 937-943 (2010).

19) Tosca, L.; Zern, T. L.; West, K. L.; Fernandez, M. L. Grape polyphenols decrease plasma triglycerides and cholesterol accumulation in the aorta ovariectomized guinea pigs. J. Nutr. 133, 2268-2272(2003).

20) Ardévol, A.; Motilva, M. J.; Serra, A.; Blay, M.; Pinent, M. Procyanidins target mesenteric adipose tissue in Wistar lean rats and subcutaneous adipose tissue in Zucker obese rat. Food Chem. 141, 160-166 (2013).

21) Rodriguez de Stillo, D. V.; Hadley, M. Chlorogenic acid modifies plasma and liver concentrations of: cholesterol, triacylglycerol, and minerals in $(f a / f a)$ Zucker rats. J. Nutr Biochem. 13, 717-726 (2002).

22) Islam, K. B. M. S.; Fukiya, S.; Hagio, M.; Fujii,N.; Ishizuka, S.; Ooka, T.; Ogura, Y.; Hayashi, T.; Yokota, A. Bile acid is a host factor that regulates the composition of the cecal microbiota in rats. Gastroenterology 141, 1773-1781 (2011).

23) Qin, Y.; Xia, M.; Ma, J.; Hao, Y. T.; Liu, J.; Mou, H. Y.; Cao, L.; Ling, W. H. Anthocyanin supplementation improves serum LDL-and HDL-cholesterol concentrations associated with the inhibition of cholesteryl ester transfer protein in dyslipidemic subjects. Am. J. Clin. Nutr. 90, 485-492 (2009).

24) Ohta, Y.; Funayama, M.; Seino, H.; Sami, M.; Kanda, T.; Shoji, T.; Ohtake, Y.; Osada, K. Apple polyphenol improves lipid metabolism and insulin independence in obese rats. Nippon Shokuhin Kagaku Kougaku Kaishi 54, 287-294(2007).

25) Noguchi, A.; Moriyama, A.; MIneo, S.; Fujisawa, Y.; Sugiyama, M.; Sakaguchi, E. Effects of long-term boysenberry juice intake on lipid accumulation in rats. $J$. Jpn. Soc. Nutr. Food Sci. 64, 27-33(2011).

26) You, Q.; Chen, F.; Wang, X.; Luo, P. G.; Jiang, Y. Inhibitory effects of muscadine anthocyanins on $\alpha$-glucosidase and pancreatic lipase activities. $J$. Agric. Food Chem. 59, 9506-9511 (2011).

27) McDougall, G. J.; Kulkarni, N. N.; Stewart, D. Berry polyphenols inhibit pancreatic lipase in vitro. Food chem. 115, 191-199(2009).

28) Taira, T.; Yamaguchi, S.; Takahashi, A.; Okazaki, Y.; Yamaguchi, A.; Sakaguchi, H.; Chiji, H. Dietary polyphenols increase fecal mucin and immunoglobulin A and ameliorate the disturbance in gut microbiota caused by a high fat diet. J. Clin. Biochem. Nutr. 57, 1-5 (2015).

29) Sasaki, R.; Nishimura, N.; Hoshino, H.; Isa, Y.; Kadowaki, M.; Ichi, T.; Tanaka, A.; Nishiumi, S.; Fukuda, I.; Ashida, H.; Horio, F.; Tsuda, T. Cyanidin 3-glucoside ameliorates hyperglycemia and insulin sensitivity due to downregulation of retinol binding protein 4 expression in diabetic mice. Biochem. Pharmacol. 74, 16191627 (2007).

30) McDougall, G. J.; Shpiro, F.; Dobson, P.; Smith, P.; Blake, A.; Stewart, D. Different polyphenolic components of soft fruits inhibit $\alpha$-amylase and $\alpha$-glucosidase. J. Agric. Food Chem. 53, 2760-2766 (2005).

31) Matsui, T.; Ebuchi, S.; Kobayashi, M.; Fukui, K.; Sugita, K.; Terahara, N.; Matsumoto, K. Anti-hyperglycemic effect of diacylated anthocyanin derived from Ipomoea batatas cultivar ayamurasaki can be achieved through the $\alpha$-glucosidase inhibitory action. J. Agric. Food Chem. 50, 7244-7248(2002).

32) Karthikesan, K.; Pari, L.; Menon, V. P. Combined treatment of tetrahydrocurcumin and chlorogenic acid exerts potential antihyperglycemic effect on streptozotocin nicotinamide-induced diabetic rats. Gen. Physiol. Biophys. 29, 23-30 (2010).

33) Dam, R. M.; Dekker, J. M.; Nijpels, G.; Stehouwer, C. D. A.; Bouter, L. M.; Heine, R. J. Coffee consumption and incidence of impaired fasting glucose, impaired glucose tolerance, and type 2 diabetes: the Hoorn Study. Diabetologia 47, 2152-2159(2004).

34) Johnston, K. L.; Clifford, M. N.; Morgan, L. M. Coffee acutely modifies gastrointestinal hormone secretion and glucose tolerance in humans: glycemic effects of chlorogenic acid and caffeine. Am. J. Clin. 78, 728$733(2003)$. 